\title{
Provider Demonstration and Assessment of Child Device Technique During Pediatric Asthma Visits
}

WHAT'S KNOWN ON THIS SUBJECT: Little is known about the extent to which providers model proper use of asthma devices to children or the extent to which providers have the children demonstrate how they use their devices during medical visits.

WHAT THIS STUDY ADDS: The majority of providers did not demonstrate or assess child use of metered dose inhalers, turbuhalers, diskuses, or peak flow meters during pediatric asthma visits.

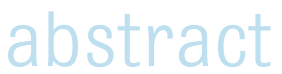

OBJECTIVE: The purposes of this study were to $(a)$ describe the extent to which children use metered dose inhalers, turbuhalers, diskuses, and peak flow meters correctly, and $(b)$ investigate how often providers assess and demonstrate use of metered dose inhalers, turbuinhalers, diskuses, and peak flow meters during pediatric asthma visits.

PATIENTS AND METHODS: Children ages 8 through 16 with mild, moderate, or severe persistent asthma and their caregivers were recruited at 5 pediatric practices in nonurban areas of North Carolina. All of the medical visits were audiotape-recorded. Children were interviewed after their medical visits, and their device technique was observed and rated by the research assistants.

RESULTS: Of the patients, 296 had useable audiotape data. Only $8.1 \%$ of children performed all of the metered dose inhaler steps correctly. Older children were more likely to get more of the metered dose inhaler steps correct. Of the children, $22 \%$ performed all of the diskus steps correctly, $15.6 \%$ performed all of the turbuhaler steps correctly, and $24 \%$ performed all of the peak flow meter steps correctly. The majority of providers did not demonstrate or assess child use of metered dose inhalers, turbuhalers, diskuses, or peak flow meters during pediatric asthma visits.

CONCLUSIONS: There is a need for providers to demonstrate proper asthma medication and monitoring device techniques to children and to have children demonstrate to proficiency. The 2007 National Heart, Lung, and Blood Institute expert panel report on the diagnosis and management of asthma encourages providers to educate children on these techniques. Pediatrics 2011;127:642-648
AUTHORS: Betsy Sleath, PhD, a,b Guadalupe X. Ayala, PhD, $\mathrm{MPH},{ }^{\mathrm{c}}$ Chris Gillette, MS, a Dennis Williams, PharmD, ${ }^{\mathrm{d}}$

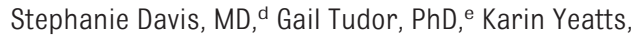
$\mathrm{PhD},{ }^{f}$ and Deidre Washington, $\mathrm{PhD}^{\mathrm{a}}$

Divisions of aPharmaceutical Outcomes and Policy and dPharmacy Practice, Eshelman School of Pharmacy, University of North Carolina, Chapel Hill, North Carolina; ${ }^{b}$ Cecil G. Sheps Center for Health Services Research, University of North Carolina, Chapel Hill, North Carolina; fDepartment of Epidemiology, School of Public Health, University of North Carolina, Chapel Hill, North Carolina; ' Division of Health Promotion and Behavioral Science, Graduate School of Public Health, San Diego State University, San Diego, California; and ${ }^{e}$ Department of Science and Mathematics, Husson University, Bangor, Maine

KEY WORDS

asthma, asthma knowledge, provider participation, patient-provider relationship

www.pediatrics.org/cgi/doi/10.1542/peds.2010-1206

doi:10.1542/peds.2010-1206

Accepted for publication Dec 28, 2010

Address correspondence to Betsy Sleath, PhD, Eshelman School of Pharmacy, University of North Carolina, Beard Hall, CB 7360, Chapel Hill, NC 27599. E-mail: betsy_sleath@unc.edu

PEDIATRICS (ISSN Numbers: Print, 0031-4005; Online, 1098-4275). Copyright (? 2011 by the American Academy of Pediatrics

FINANCIAL DISCLOSURE: The authors have indicated they have no financial relationships relevant to this article to disclose.

Funded by the National Institutes of Health (NIH). 
Asthma is a worldwide problem, and it is the most common chronic condition among American children.1,2 Health care costs for asthma are estimated at more than $\$ 6$ billion a year, and loss in productivity by working parents caring for children who miss school because of asthma is estimated at $\$ 1$ billion a year. 3,4

It has been demonstrated in previous research that children often do not properly use metered dose inhalers, turbuhalers, and other asthma devices. ${ }^{5-7}$ Children's improper use of inhalers and other asthma medication devices can lead to poor asthma control, increased number of hospitalizations, and increased health care costs. ${ }^{8-10}$

Social cognitive theory is a relevant theoretical framework for understanding children's use of asthma devices, including devices to administer medication and monitor symptoms. ${ }^{11}$ Self-efficacy is 1 of the key constructs in social cognitive theory. ${ }^{12}$ According to the theory, individuals with higher levels of self-efficacy to perform a certain behavior such as using an inhaler or peak flow meter are more likely to undertake the behavior. ${ }^{13,14}$ Providers can model the use of inhalers, peak flow meters, and other devices during asthma visits, and they can have children demonstrate how they use inhalers and peak flow meters during medical visits. In fact, a 2007 National Heart Lung and Blood Institute expert panel report emphasizes that providers should demonstrate proper inhaler technique and other asthma device techniques and have the child return the demonstration. ${ }^{3}$

To our knowledge, no previous study has examined the extent to which providers model proper use of asthma devices to children or the extent to which providers have the children demonstrate how they use their devices so they can identify children who are not using them properly. Therefore, the purposes of this study were to $(a)$ describe the extent to which children use metered dose inhalers, turbuhalers, diskuses, and peak flow meters correctly, and (b) investigate how often providers assess and demonstrate use of metered dose inhalers, turbuinhalers, diskuses, and peak flow meters during pediatric asthma visits.

\section{METHODS}

\section{Participants}

The study was approved by the University of North Carolina's institutional review board. Providers were recruited at 5 pediatric practices in North Carolina, and consent was obtained. Children and their caregivers of these participating providers were recruited. Children were eligible if they $(a)$ were ages 8 to 16, (b) were able to speak English, (c) could read the assent form, $(d)$ had been seen at the clinic at least once before, (e) were present at the visit with an adult caregiver (parent or legal guardian) who could read and speak English and who was at least 18 years of age, and $(f)$ had mild, moderate, or severe persistent asthma. Persistent asthma was defined as experiencing asthma-related daytime symptoms more than twice a week, asthma-related nighttime symptoms more than twice a month, or receiving 1 or more long-term controller therapies for asthma. ${ }^{15,16}$

Clinic staff referred to a research assistant potentially eligible patients who were interested in learning more about the study. The research assistant explained the study, obtained caregiver consent and child assent, and administered the eligibility screener. ${ }^{4}$ Providers and families were told that the study was examining communication during pediatric visits. All of the medical visits were audiotape-recorded. Children were interviewed after their medical visits, and their device technique was ob- served and rated by the research assistants. Caregivers completed selfadministered questionnaires.

\section{Audiotape Coding}

All of the medical visit audiotapes were transcribed verbatim. A detailed coding tool was developed and tested during a 1-year period. All of the transcripts were coded. Two research assistants coded 20 of the same transcripts throughout the study period to assess inter-coder reliability.

\section{Measures}

Demographic and Sociodemographic Characteristics

Medication use was assessed on the caregiver screener. The research assistants showed caregivers a list of asthma medications and asked them to indicate which one or ones the child was taking. Responses were dichotomized on the basis of whether the caregiver reported that the child was on a controller medication versus not on a controller medication. Asthma severity was classified as mild versus moderate/severe by a research assistant on the basis of recent symptoms and medication use reported by the caregivers when research assistants administered the eligibility screening instrument for the study. ${ }^{4,15,16}$ Our eligibility screening instrument used the primary asthma severity classification system that was being used when the study was designed and conducted. $4,15,16$

All child study information was then reviewed by a pediatric pulmonologist or a clinical pharmacist with expertise in asthma to verify the severity classification as mild or moderate/severe persistent asthma. Severity was classified using 2 different methods. In situations in which the 2 methods resulted in discordant classification, the more severe category was used. The first method was medication use; any child 
who received a single long-term control agent was considered to have mild persistent asthma. Any child who received 2 or more long-term control agents was categorized as moderate to severe persistent asthma. The second method classified severity on the basis of symptom frequency. Any child who reported the occurrence of any 1 of 8 symptoms as occurring 2 or more times a week or who reported awakening with asthma symptoms 2 or more times a month was classified as mild persistent. Reports of daily symptom occurrence or of awakening $\geq 5$ times a month resulted in a classification as moderate or severe persistent.

A variety of demographic and sociocultural factors were examined as potential confounders. For descriptive purposes, child race was recoded into 4 categories: white; black; Native American/American Indian; or other. However, for the bivariate analyses, child race was recoded into a dichotomous variable (white versus nonwhite). The child's insurance status was measured using the following categories: none; private insurance; Medicaid; the State Children's Health Insurance Program; and other.

\section{Asthma Medication and Peak Flow Meter Technique}

The pediatric pulmonologist and clinical pharmacist who specializes in asthma on our team developed how device technique would be assessed using the peer-reviewed literature and their clinical experience. ${ }^{17-19}$ Five research assistants underwent training to assess inhalation device technique. These research assistants who assessed device technique were different from those who coded the audiotape data. A DVD was created with examples of optimal technique with each device, and scoring sheets for research assistants were developed. Three children were then recorded us- ing the various devices with varying omissions and errors. The devices used for the DVD were (1) metered dose inhaler, (2) dry powder inhaler (DPI-Diskus), (3) dry powder inhaler (DPI-Turbuhaler), and (4) a peak flow meter. The research assistants viewed and scored the example techniques using the study criteria. These results were reviewed by a clinical pharmacist investigator who provided feedback about the research assistant scoring on the basis of his clinical judgment. Each research assistant was asked to review the DVD recording again until concordance was reached among all participants.

Immediately after the audiotaped medical visit, all children were asked if they used each of the devices. If they reported that they did, they were then asked to demonstrate their technique using placebo devices provided by the research staff. There were 43 children who brought their own devices with them to their medical visits. Metered dose inhaler technique had 8 possible correct steps (Table 1). After demonstrating the metered dose inhaler, children were asked if they usually used a spacer. If they stated yes, they were asked to then demonstrate using an inhaler with a spacer. Using a metered dose inhaler with a spacer had 8 possible steps correct (Table 1). Diskus technique had 7 possible correct steps (Table 2). Turbuhaler technique had 7 possible correct steps (Table 3). Peak flow technique had 8 possible correct steps (Table 4).

\section{Provider Demonstration and Assessment of Child Technique During Visits}

Coders of the transcripts of the medical visits recorded the following: provider demonstrates metered dose inhaler technique; diskus technique; turbuhaler technique; and peak flow technique. Coders also recorded
TABLE 1 Metered Dose Inhaler Device Technique

\begin{tabular}{|c|c|}
\hline & $\begin{array}{l}\text { Percent } \\
\qquad(M)\end{array}$ \\
\hline \multicolumn{2}{|l|}{$\begin{array}{l}\text { Steps used by all children who } \\
\text { stated they used a metered } \\
\text { dose inhaler }(N=270)\end{array}$} \\
\hline Remove cap from inhaler & $97.3(256)$ \\
\hline Shake inhaler 4-6 times & $44.4(116)$ \\
\hline Exhale normally & $36.2(93)$ \\
\hline $\begin{array}{l}\text { Tilt head back slightly, with } \\
\text { inhaler upright, place } \\
\text { mouthpiece between lips or } \\
\text { 1-2 inches in front of a } \\
\text { wide open mouth }\end{array}$ & $83.9(218)$ \\
\hline Between a slow deep breath & $81.7(214)$ \\
\hline $\begin{array}{l}\text { Press inhaler canister once at } \\
\text { beginning of breath }\end{array}$ & $84.0(220)$ \\
\hline Continue to inhale for $3-4 \mathrm{~s}$ & $63.9(166)$ \\
\hline Hold breath for $10 \mathrm{~s}$ & $32.6(85)$ \\
\hline $\begin{array}{l}\text { Wait at least } 30 \text { s and repeat } \\
\text { steps 2-8 if using another } \\
\text { puffa }\end{array}$ & $27.2(69)$ \\
\hline $\begin{array}{l}\text { Children who performed all } \\
\text { steps correctly }\end{array}$ & $8.1(22)$ \\
\hline $\begin{array}{l}\text { Steps used by children who } \\
\text { stated they usually used a } \\
\text { spacer who demonstrated } \\
\text { spacer use }(N=69)\end{array}$ & $94.1(64)$ \\
\hline Remove cap from inhaler & \\
\hline $\begin{array}{l}\text { Attach inhaler into holding } \\
\text { chamber }\end{array}$ & $95.5(64)$ \\
\hline Shake inhaler 4-6 times & $42.4(28)$ \\
\hline Exhale normally & $52.2(35)$ \\
\hline $\begin{array}{l}\text { Tilt head back slightly, place } \\
\text { holding chamber } \\
\text { mouthpiece between lips, } \\
\text { holding inhaler upright }\end{array}$ & $80.6(54)$ \\
\hline $\begin{array}{l}\text { Press inhaler canister once to } \\
\text { place dose in holding } \\
\text { chamber }\end{array}$ & $91.0(61)$ \\
\hline $\begin{array}{l}\text { Begin a slow deep inhalation } \\
\text { immediately after placing } \\
\text { dose in holding chamber } \\
\text { (3-4 s) }\end{array}$ & $83.6(56)$ \\
\hline Hold breath for $10 \mathrm{~s}$ & $46.3(31)$ \\
\hline $\begin{array}{l}\text { Wait at least } 30 \mathrm{~s} \text { and repeat } \\
\text { steps above if using } \\
\text { another puffa }\end{array}$ & $40.3(27)$ \\
\hline $\begin{array}{l}\text { Children who performed all } \\
\text { steps correctly }\end{array}$ & $20.3(14)$ \\
\hline
\end{tabular}

whether the provider asked the child to demonstrate how they use their metered dose inhaler, diskus, turbuhaler, and peak flow meter (if applicable). Two research assistants coded 20 of the same transcripts throughout the study period to as- 
TABLE 2 Diskus Device Technique $(N=105)$

\begin{tabular}{ll}
\hline & $\begin{array}{c}\text { Percent } \\
(M)\end{array}$ \\
\hline Step & \\
$\quad$ Open device until it clicks & $99.0(103)$ \\
To load a dose, hold device & $72.8(75)$ \\
$\quad$ horizontal and slide the & \\
$\quad$ lever away from you & \\
$\quad$ until it stops (there & \\
$\quad$ should be a second & \\
click) & \\
Exhale gently away from & \\
$\quad$ mouthpiece & $39.6(40)$ \\
Place mouthpiece in lips & \\
$\quad$ Take a forceful breath in & $99.0(103)$ \\
$\quad$ steadily and deeply & $89.2(91)$ \\
Hold breath for 10 s & \\
Close device by sliding & $42.2(43)$ \\
$\quad$ thumb grip toward self & $96.1(99)$ \\
$\quad$ until it clicks & \\
Children who performed all & \\
$\quad$ steps correctly & $21.9(23)$ \\
\hline
\end{tabular}

TABLE 3 Turbuhaler Device Technique $(N=45)$

\begin{tabular}{lc}
\hline & $\begin{array}{c}\text { Percent } \\
(M)\end{array}$ \\
\hline $\begin{array}{l}\text { Step } \\
\text { Lift off white cover to reveal }\end{array}$ & $63.6(28)$ \\
$\quad$ mouthpiece & \\
Hold device with mouthpiece up & $69.1(29)$ \\
$\quad$ and twist the grip at the base, & \\
$\quad$ back and forth 1 time to load & \\
$\quad$ dose & \\
Hold device horizontal and exhale & $29.3(12)$ \\
$\quad$ gently, away from mouthpiece & \\
$\quad$ Place mouthpiece between lips & $100.0(40)$ \\
$\quad$ Take a forceful breath in steadily & $87.8(36)$ \\
$\quad$ and deeply & \\
$\quad$ Hold breath for 10 s & $41.5(17)$ \\
If second dose is required, repeat & $35.1(13)$ \\
$\quad$ steps 2-6 & \\
$\quad$ Replace white cover & $60.0(24)$ \\
Children who performed all steps & $15.6(7)$ \\
$\quad$ correctly & \\
\hline
\end{tabular}

a This step was not included in the calculation of children who performed all steps correctly because some children may or may not have been prescribed a second dose.

sess inter-coder reliability. However, provider demonstration of device technique and asking the child to demonstrate device technique happened so infrequently that intercoder reliability statistics could not be calculated. However, there was $100 \%$ coder agreement on the provider demonstrating metered dose inhaler technique, the provider ask-
TABLE 4 Peak Flow Device Technique $(N=67)$

\begin{tabular}{lc}
\hline & $\begin{array}{c}\text { Percent } \\
(M)\end{array}$ \\
\hline Step & \\
Set marker to 0 & $68.2(45)$ \\
Hold meter upright & $90.9(60)$ \\
Do not block marker movement & $86.6(57)$ \\
Deep breath in with mouth open & $84.6(55)$ \\
Place meter in mouth and close & $92.5(62)$ \\
$\quad$ lips tightly around meter & \\
Exhale hard and fast into meter & $87.9(58)$ \\
Check the result & $83.6(56)$ \\
$\quad$ Repeat steps 1-7 two more & $56.9(37)$ \\
$\quad$ times & \\
Children who performed all steps & $23.9(16)$ \\
$\quad$ correctly & \\
\hline
\end{tabular}

ing the child to demonstrate their metered dose inhaler technique, and the provider asking the child to demonstrate their diskus technique. There was $95 \%$ coder agreement for provider demonstrating peak flow technique and diskus technique and the provider asking the child to demonstrate turbuhaler technique and peak flow technique. There was $90 \%$ coder agreement for the provider demonstrating turbuhaler technique.

\section{Statistical Analysis}

All analyses were conducted using SPSS (SPSS Inc, Chicago, IL). First, we presented descriptive statistics for the variables. Second, we examined bivariate relationships between the demographic variables using correlation coefficients, $t$ tests, or Pearson $\chi^{2}$ statistics. If there was a significant bivariate relationship between a demographic characteristic and device technique, then a multivariable analysis was conducted to investigate whether the relationship was still significant after controlling for other variables. Child age, gender, race, years with asthma, asthma severity, and caregiver education were included in the multivariable models that predicted metered dose inhaler technique and peak flow technique.

\section{RESULTS}

The 5 participating clinics were all primary care pediatric practices. There were 41 providers who agreed to participate in the study. Two providers refused to participate for a participation rate of $95.3 \%$. Eightyeight percent of the families approached agreed to participate in the study. There were 296 patients who had useable audiotape data, and these patients were seen by 35 of the 41 providers who agreed to participate in the study. Four of the 35 providers were nurse practitioners or physician assistants, and they saw 17 of the participating children. Of the providers, $51 \%$ were female. Twenty-seven of the providers were white, 2 were American Indian, 3 were black, 1 was Asian, and 2 classified their race as other. Providers ranged in age from 30 to 70 years (mean: 44.8 years; SD: 9.4). Table 5 presents the child and caregiver demographic characteristics.

\section{Metered Dose Inhaler Technique}

Of the children, $91 \%(N=270)$ reported that they used metered dose inhalers. As shown in Table 2 only $8.1 \%$ of children performed all of the steps correctly. Older children were significantly more likely to get more of the steps correct (Pearson's $r=$ $0.20, P=.001)$. Children of caregivers who had more years of education were significantly more likely to get more of the steps correct (Pearson's $r=$ $0.14, P=.03$ ). Child age remained significant in the multivariable analysis (Table 6). However, years of caregiver education became insignificant $(P=.05)$.

Providers asked only $5.4 \%$ of all children who reported using metered dose inhalers and only $2.3 \%$ of children (3 of 129) who got fewer than 6 steps correct on metered dose inhaler technique to demonstrate their 
TABLE 5 Child and Caregiver Demographic Characteristics $(N=296)$

\begin{tabular}{|c|c|}
\hline & Percent $(M)$ \\
\hline \multicolumn{2}{|l|}{ Child age, y } \\
\hline Mean (SD) (range) & $11.1(2.4)(8-16)$ \\
\hline \multicolumn{2}{|l|}{ Child gender } \\
\hline Male & 53.7 (159) \\
\hline Female & $46.3(137)$ \\
\hline \multicolumn{2}{|l|}{ Child race } \\
\hline White & $61.5(182)$ \\
\hline Black & 30.1 (89) \\
\hline $\begin{array}{l}\text { Native American/American } \\
\text { Indian }\end{array}$ & $10.1(30)$ \\
\hline Other & $6.1(18)$ \\
\hline \multicolumn{2}{|l|}{ Asthma severity } \\
\hline Mild persistent & $28(83)$ \\
\hline $\begin{array}{l}\text { Moderate/severe } \\
\text { persistent }\end{array}$ & $72(213)$ \\
\hline \multicolumn{2}{|l|}{ No. years living with asthma } \\
\hline Mean (SD) (range) & $6(3.9)(9-16)$ \\
\hline \multicolumn{2}{|l|}{$\begin{array}{l}\text { Child's caregiver marital } \\
\text { status }\end{array}$} \\
\hline Never & $16.2(48)$ \\
\hline Married & $57.8(171)$ \\
\hline Separated & $9.5(28)$ \\
\hline Divorced & $12.5(37)$ \\
\hline Widowed & $3.0(9)$ \\
\hline \multicolumn{2}{|l|}{ Caregiver age, y } \\
\hline Mean (SD) (range) & $42(8.4)(27-81)$ \\
\hline \multicolumn{2}{|l|}{ Caregiver gender } \\
\hline Male & $14.2(42)$ \\
\hline Female & $85.8(253)$ \\
\hline \multicolumn{2}{|l|}{ Caregiver education, y } \\
\hline Mean (SD) (range) & $12.8(2.5)(2-20)$ \\
\hline \multicolumn{2}{|l|}{ Insurance type } \\
\hline None & $1.0(3)$ \\
\hline Private & $26.4(78)$ \\
\hline Medicaid & $51.7(153)$ \\
\hline $\begin{array}{l}\text { State Children's Health } \\
\text { Insurance Program }\end{array}$ & $17.6(52)$ \\
\hline Other & $2.7(8)$ \\
\hline \multicolumn{2}{|l|}{ Device use } \\
\hline Metered dose inhaler & $91.2(270)$ \\
\hline Diskus & 35.5 (105) \\
\hline Turbuhaler & $15.2(45)$ \\
\hline Peak flow & $22.6(67)$ \\
\hline
\end{tabular}

technique during the medical visit. The provider demonstrated metered dose inhaler technique to only $3.8 \%$ of all children and to only $2.3 \%$ (3 of 129) of the children who got fewer than 6 steps correct when demonstrating their metered dose inhaler technique. Only 1 child who got fewer than 6 steps correct was asked to demonstrate their technique and also was shown proper technique by the provider during the visit.
TABLE 6 Multiple Linear Regression Examining Factors Associated With Child Metered Dose Inhaler Technique $(N=270)$ and Peak Flow Technique $(N=67)$

\begin{tabular}{lcc}
\hline $\begin{array}{c}\text { Independent } \\
\text { Variables }\end{array}$ & $\begin{array}{c}\text { Inhaler } \\
\text { Technique } \beta\end{array}$ & $\begin{array}{c}\text { Peak Flow } \\
\text { Technique } \beta\end{array}$ \\
\hline $\begin{array}{l}\text { Child's gender is } \\
\text { female }\end{array}$ & 0.03 & 0.18 \\
Child's age, y & $2.96^{\mathrm{a}}$ & 0.24 \\
Child's race is white & 0.03 & $-0.39^{\mathrm{b}}$ \\
Severity of asthma is & -0.02 & -0.23 \\
$\quad$ moderate/severe & & \\
Years with asthma & 0.01 & 0.24 \\
Caregiver years of & 0.12 & 0.06 \\
$\quad$ education & & \\
\hline a $P<.01$. & & \\
b $P<.05$. & &
\end{tabular}

\section{Diskus Technique}

Thirty-six percent $(N=105)$ of the children reported that they used diskus devices. As shown in Table 2, only $22 \%$ of children performed all of the diskus steps correctly. Providers asked 14.3\% of all children who used a diskus and only $9.4 \%$ of children (3 of 32) who got fewer than 5 steps correct on diskus technique to demonstrate their technique during the medical visit. Providers demonstrated diskus technique to only $11.4 \%$ of all children who reported using 1 and to only $9.4 \%$ of children (3 of 32) who got fewer than 5 steps correct when demonstrating their diskus technique. Only 1 of the children who got fewer than 5 steps correct was asked to demonstrate their technique and also was shown proper technique by the provider during the visit.

\section{Turbuhaler Technique}

Fifteen percent $(N=45)$ of the children reported that they used turbuhalers. Table 3 illustrates that only $15.6 \%$ of the children performed all the steps correctly. Providers asked only $4.4 \%$ of all children using turbuhalers and none of the children (0 of 16) who got fewer than 5 steps correct on turbuhaler technique to demonstrate their technique. Providers demonstrated turbuhaler technique to only 1 of the children who were on turbuhalers, and they did not demonstrate how to use a turbuhaler to any of the children who got fewer than 5 steps correct when their turbuhaler technique was assessed.

\section{Peak Flow Technique}

Twenty-three percent of the children reported that they used peak flow meters. In Table 4 it is shown that only $24 \%$ of children who reported using peak flow meters performed all of the peak flow meter steps correctly. Nonwhite children were significantly more likely to get more of the peak flow meter steps done correctly than were white children ( $t$ test $=2.43, P=.018$ ). Child race remained significant in the multivariable analysis (Table 3). Providers asked only 2 of all of the children who reported using peak flow meters and none of the children who got $<5$ of the steps correct on peak flow technique to demonstrate how they used a peak flow meter. Providers demonstrated peak flow technique to only 2 of all children who reported using peak flow meters, and they did not demonstrate peak flow technique to any of the children who got $<5$ of the steps correct on peak flow technique.

\section{DISCUSSION}

The majority of providers are not taking the time to demonstrate or assess child use of metered dose inhalers, turbuhalers, diskuses, or peak flow meters during pediatric asthma visits despite the fact that our results indicate that many children are not using them correctly. Providers should demonstrate any asthma devices that a specific child needs to use to the child and his/her family and then have the child demonstrate back how he/she would use the devices. This is what the National Heart Lung and Blood Institute expert guidelines suggest that providers do when educating patients with asthma. Future research should examine what barriers exist to providers 
demonstrating and assessing child use of devices.

The more that children can be shown how to use devices and have time to practice using them during medical visits and receive feedback on their technique, the more opportunity there is to build behavioral capacity and selfefficacy. If children have greater behavioral capacity and self-efficacy for using the devices, they are more likely to use them and to use them correctly, which could lead to better health outcomes. Modeling and skill development are important components of social cognitive theory ${ }^{11,12}$ and are instrumental for improving behavioral capacity and self-efficacy.

We found that many children with asthma are not correctly using their metered dose inhalers, diskuses, turbuhalers, or peak flow meters. Practices should consider using allied health professionals to demonstrate or assess device technique with children with asthma when their providers do not have time to do so. ${ }^{20-24}$

In addition to providers showing patients how to correctly use asthma devices, patients and their families could be encouraged to ask their community pharmacists about proper use of these devices. ${ }^{8}$ Pharmacists can be a valuable resource for patients in providing counseling and education regarding inhaler use. ${ }^{25-27} \mathrm{Im}$ proving proper use of inhalers and other devices could lead to improved patient outcomes. ${ }^{8-10}$

Metered dose inhalers and diskuses were the most common devices that

\section{REFERENCES}

1. National Academy on an Aging Society. Childhood asthma: the most common chronic disease among children. 2000. Available at: www.agingsociety.org/ agingsociety/pdf/asthma.pdf. Accessed March 1, 2009

2. National Center for Health Statistics. Summary health statistics for US children: $\mathrm{Na}$ - children reported using. The most common steps that children missed for metered dose inhaler and diskus technique were $(a)$ exhaling normally before using the metered dose inhaler or diskus, and $(b)$ holding their breath for at least 10 seconds after inhaling. Providers could emphasize the importance of these steps to children and their families.

It is interesting that children of more educated caregivers were significantly more likely to get more of the correct metered dose inhaler steps right in the bivariate analysis. Although caregiver education became insignificant in the multivariable analysis, it might have been significant with a larger sample size. This finding illustrates the importance of educating children and caregivers about the proper use of inhalers so that they can practice proper use of them before leaving the clinic. Involving children directly in the demonstration and practice of device use is consistent with the US Pharmacopeia principles regarding the rights of children and adolescents to receive developmentally appropriate and direct communication about medicines. ${ }^{28}$

Older children were significantly more likely to get more of the metered dose inhaler steps correct. Therefore, care must be taken to help ensure that younger children know how to properly use their inhalers. Demonstrating proper use and having children practice while at the clinic could help improve use of the devices.

tional Health Interview Survey. 2008. Centers for Disease Control and Prevention. Available at: www.cdc.gov/nchs/data/ series/sr 10/sr10 244.pdf. Accessed March 1, 2009

3. National Asthma Education and Prevention Program. Expert Panel Report 3 (EPR-3): Guidelines for the Diagnosis and Management of Asthma-
The study is limited in generalizability in that it was conducted in 5 pediatric clinics in nonurban areas of North Carolina. A second limitation is that we do not know how many patients who the clinic staff referred chose not to talk with the research assistant. However, we could not ask the clinic staff to track these numbers because of the busyness of the clinic and our promise not to interrupt clinic flow. A third limitation is that we measured provider type as physician versus nurse practitioner or physician assistant. We cannot distinguish between nurse practitioners and physician assistants. A fourth limitation is that we did not assess whether the adult caregiver was the primary caretaker of the child. Another limitation is that we chose audiotaping rather than videotaping the medical visits because it is less intrusive, and fewer individuals mind being audiotaped as opposed to being videotaped. Another limitation is that we do not know if these children were referred for asthma education or specialist care. Despite the limitations of the study, it presents observed data on children's use of asthma devices and audiotaped data on the extent to which providers model and have children demonstrate their use of asthma devices during medical visits.

\section{ACKNOWLEDGMENT}

This study was funded by National Heart Lung and Blood Institute grant HL069837 and in part by National Center for Research Resources (National Institutes of Health) grant UL 1RR025747.

Summary Report 2007. J Allergy Clin Immunol. 2007;120(5 suppl):S94-S138

4. National Asthma Education and Prevention Program. Expert Panel Report: Guidelines for the Diagnosis and Management of Asthma, Update on Specific Topics. Washington, DC: National Institutes of Health; 2002. Publication 02-5075 
5. Goren A, Noviski N, Avital A, et al. Assessment of the ability of young children to use a powder inhaler device (Turbuhaler). Pediatr Pulmonol. 1994;18(2):77-80

6. Boccuti L, Celano M, Geller RJ, Phillips KM. Development of a scale to measure children's metered-dose inhaler and spacer technique. Ann Allergy Asthma Immunol. 1996;77 (3):217-221

7. Larsen JS, Hahn H, Ekholm B, Wick KA. Evaluation of conventional press-and-breathe metered-dose inhaler technique in 501 patients. J Asthma. 1994;31(3):1993-1999

8. Basheti IA, Armour CL, Bosnic-Anticevich SZ, Raddel HK. Evaluation of a novel educational strategy, including inhaler-based reminder labels, to improve asthma inhaler technique. Patient Educ Couns. 2008;72(1): $26-33$

9. Chopra N, Oprescu N, Fask A, Oppenheimer J. Does introduction of new "easy to use" inhalational devices improve medical personnel's knowledge of their proper use? Ann Allergy Asthma Immunol. 2002;88(4): 395-400

10. Giraud V, Roche N. Misuse of corticosteroid metered-dose inhaler is associated with decreased asthma stability. Eur Respir J. 2002;19(2):246-251

11. Baranowski T, Perry CL, Parcel GS. How individuals, environments, and health behavior interact: social cognitive theory. In: Glanz K, Rimer BK, Lewis FM, eds. Health Behavior and Health Education. Hoboken, $\mathrm{NJ}$ : John Wiley and Sons; 2002:165-184

12. Bandura A. Social Foundation of Thought and Action: a Social Cognitive Theory. Englewood Cliffs, NJ: Prentice-Hall; 1986

13. Bandura A. Human agency in social cogni- tive theory. Am Psychol. 1989;44(9): 1175-1184

14. DeVellis BM, DeVellis RF. Self-efficacy and health. In: Baum A, Revenson TA, Singer JE, eds. Handbook of Health Psychology. Mahwah, $\mathrm{NJ}$ : Lawrence Erlbaum Associates; 2000:235-247

15. National Heart Lung and Blood Institute. Guidelines for the Diagnosis and Management of Asthma, Expert Panel Report 2. Bethesda, MD: National Institutes of Health; 1997. Publication No. 97-405

16. Cabana MD, Slish KK, Nan B, Clark NM. Limits of the HEDIS criteria in determining asthma severity for children. Pediatrics. 2004; 114(4):1049-1055

17. Erickson SR, Horton A, Kirking DM. Assessing metered-dose inhaler technique: comparison of observation vs. patient selfreport. J Asthma. 1998;35(7):575-583

18. Gray SL, Nance AC, Williams DM, Pulliam CC. Assessment of interrater and intrarater reliability in the evaluation of metered dose inhaler technique. Chest. 1994;105(3): 710-714

19. Melani AS, Zanchetta D, Barbato N, et al. Inhalation technique and variables associated with misuse of conventional metereddose inhalers and newer dry powder inhalers in experienced adults. Ann Allergy Asthma Immunol. 2004;93(5):439-446

20. Wroth TH, Boals JC IV. Application of qualityimprovement methods in a community practice: the Sandhills Pediatrics Asthma Initiative. N C Med J. 2005;66(3):218-220

21. Garvey C. Advances in asthma care: asthma educator certification. Californian J Health Promot. 2003;1(1):87-90

22. Bravata DM, Gienger AL, Holty JE, et al. Qual- ity improvement strategies for children with asthma: a systematic review. Arch Pediatr Adolesc Med. 2009;163(6):572-581

23. Bunting BA, Cranor CW. The Asheville Project: long-term clinical, humanistic, and economic outcomes of a community-based medication therapy management program for asthma. J Am Pharm Assoc (2003). 2006; 46(2): 133-147

24. Bosnic-Anticevich SZ, Sinha H, So S, Reddel HK. Metered-dose inhaler technique: the effect of two educational interventions delivered in community pharmacy over time. J Asthma. 2010;47 (3):251-256

25. Basheti IA, Reddel HK, Armour CL, BosnicAnticevich SZ. Improved asthma outcomes with a simple inhaler technique intervention by community pharmacists. J Allergy Clin Immunol. 2007;119(6):1537-1538

26. Holzheimer L, Mohay H, Masters IB. Educating young children about asthma: comparing the effectiveness of a developmentally appropriate asthma education video tape and picture book. Child Care Health Dev. 1998;24(1):85-99

27. Jowers JR, Schwartz AL, Tinkelman DG, et al. Disease management program improves asthma outcomes. Am J Manag Care. 2000; 6(5):585-592

28. Basheti IA, Reddel HK, Armour CL, BosnicAnticevich SZ. Counseling about Turbuhaler technique: needs assessment and effective strategies for community pharmacists. Respir Care. 2005;50(5):617-623

29. Bush P, Ozias J, Walson P, Ward R. Ten guiding principles for teaching children and adolescents about medicines. Clin Ther. 1999; 21(7):1280-1284 